\title{
ChIP-on-chip analysis of thyroid hormone-regulated genes and their physiological significance
}

\author{
I-Hsiao Chung ${ }^{1 *}$, Hsuan Liu ${ }^{1,2,6 *}$, Yang-Hsiang Lin ${ }^{1}$, Hsiang-Cheng Chi ${ }^{1}$, Ya-Hui \\ Huang $^{3}$, Chang-Ching Yang ${ }^{2,4}$, Chau-Ting Yeh ${ }^{3}$, Bertrand Chin-Ming Tan ${ }^{2,4,5}$, Kwang- \\ Huei Lin ${ }^{1,3}$ \\ ${ }^{1}$ Department of Biochemistry, College of Medicine, Chang Gung University, Taoyuan, Taiwan \\ ${ }^{2}$ Molecular Medicine Research Center, Chang Gung University, Taoyuan, Taiwan \\ ${ }^{3}$ Liver Research Center, Chang Gung Memorial Hospital, Linkou, Taoyuan, Taiwan \\ ${ }^{4}$ Department of Biomedical Sciences, College of Medicine, Chang Gung University, Taoyuan, Taiwan \\ ${ }^{5}$ Department of Neurosurgery, Chang Gung Memorial Hospital, Taoyuan, Taiwan \\ ${ }^{6}$ Colorectal Section, Chang Gung Memorial Hospital, Linkou, Taoyuan, Taiwan \\ *These authors have contributed equally to this work \\ Correspondence to: Bertrand Chin-Ming Tan, e-mail: btan@mail.cgu.edu.tw \\ Kwang-Huei Lin, e-mail: Khlin@mail.cgu.edu.tw
}

Keywords: thyroid hormone receptor, ChIP-on-chip, cell growth, ELF2

Received: October 30, $2015 \quad$ Accepted: February 23, $2016 \quad$ Published: March 8, 2016

\section{ABSTRACT}

Triiodothyronine $\left(T_{3}\right)$ and its receptor (TR) modulate several physiological processes, including cell development, proliferation, differentiation and metabolism. The regulatory mechanism of $\mathrm{T}_{3} / \mathrm{TR}$ involves binding to the thyroid hormone response element (TRE) within the target gene promoter. However, the number of target genes directly regulated by TRa1 and the specific pathways of TR-regulated target genes remain largely unknown. Here, we expressed TRa1 in a HepG2 cell line and used chromatin immunoprecipitation coupled with microarray to determine the genes that are directly regulated by TRa1 and also involved in cell metabolism and proliferation. Our analysis identified E74-like factor 2 (ELF2), a transcription factor associated with tumor growth, as a direct target downregulated by $T_{3} / T R$. Overexpression of ELF2 enhanced tumor cell proliferation, and conversely, its knockdown suppressed tumor growth. Additionally, ELF2 restored the proliferative ability of hepatoma cells inhibited by $T_{3} / T R$. Our findings collectively support a potential role of $T_{3} / T R$ in tumor growth inhibition through regulation of ELF2.

\section{INTRODUCTION}

Thyroid hormone receptors (TRs) are liganddependent transcription factors that mediate biological activities, such as cell growth, development and differentiation of the thyroid hormone (TH) [1-4]. Human TRs belong to a superfamily of nuclear receptors, and are encoded by THRA and THRB genes located on human chromosomes 17 and 3, respectively [5]. The two functional receptor isoforms, TR $\alpha 1$ and TR $\beta 1$, are expressed at different levels across various tissues and bind $\mathrm{T}_{3}$. TR binds as a monomer, homodimer, or heterodimer with retinoid $\mathrm{X}$ receptor (RXR) at thyroid hormone response elements (TREs) to regulate target gene transcription [6-8]. In $\mathrm{T}_{3}$-depleted conditions, TRs recruit nuclear corepressors for transcriptional repression of genes positively regulated by $\mathrm{T}_{3}$. Conversely, $\mathrm{T}_{3}$-bound TR undergoes conformational changes that result in release of co-repressors, allowing recruitment of nuclear receptor coactivators to facilitate transcriptional activation $[9,10]$. A number of recent studies have attempted to characterize the functions and mechanisms underlying the positive or negative transcriptional regulation of TR $\beta 1$ [11-13]. However, limited information is available on genes directly regulated by TR $\alpha 1$ that are involved in critical pathways.

While several TR $\alpha 1$-regulated target genes have been identified in liver, their regulatory mechanisms and functional effects have not been reported to date [14]. A previous microarray study did not address whether these effects are directly or indirectly regulated by TR $\alpha 1$. Recently, 
the TR $\alpha 1$ and TR $\beta 1$ cistromes were analyzed in a neural cell line using overexpressed, tagged receptors, revealing that the two receptor isoforms share some overlap in binding sites but also have unique targets [15]. However, it remains to be established whether $\mathrm{T}_{3}$ can directly and specifically regulate TR $\alpha 1-$ binding genes in hepatoma cell lines.

To characterize the TR $\alpha 1$ binding sites in a hepatoma cell line, we performed chromatin affinity precipitation coupled with microarray under $T_{3}$ treatment conditions. Notably, $\mathrm{T}_{3}$ treatment enhanced TR $\alpha 1$ binding both positively and negatively at distinct genomic sites, and these changes were strongly correlated with those in the expression of associated genes. These results support a specific mechanism underlying the regulation of target genes by TR $\alpha 1$ whereby transcriptional changes are effected by $\mathrm{T}_{3}$ dictating differential binding of $\mathrm{TR} \alpha 1$ through preferred motifs.

The E26 transformation-specific (ETS) family has been increasingly recognized as key regulators of cell differentiation, hormone responses and tumorigenesis in target tissues $[16,17]$. The ETS family of genes is highly diverse, consisting of both transcriptional activators and repressors that mediate growth factor signaling and regulate gene expression through interactions with multiple protein partners [18]. ELF2, belonging to the ETS family, is associated with cell proliferation [19] and downregulated by $\mathrm{T}_{3} / \mathrm{TR}$. In the current study, we focused on the role of ELF2 and mechanisms underlying its regulation by $\mathrm{T}_{3} / \mathrm{TR}$ in a hepatoma cell line. Based on the collective findings, we propose that $\mathrm{T}_{3} / \mathrm{TR}$ suppresses cell proliferation through downregulation of ELF2 in HCC.

\section{RESULTS}

\section{ChIP-on-chip analysis of gene binding in HepG2-TRa1 cells}

A HepG2 cell line stably expressing high levels of wild-type TR $\alpha 1$ (HepG2-TR $\alpha 1$ ) was established for analyses (Figure 1A, upper panel). Well-known TRbinding genes, such as Furin [21], Glu5 [22] and Dio [23], were employed to determine direct regulation by $\mathrm{T}_{3} / \mathrm{TR}$ using the ChIP assay. TR proteins were clearly associated with the TRE region within Furin, Glu5 and Dio promoters in vivo (Figure 1A, lower panel and Figure 1B). TR $\alpha 1$ was recruited to the TRE-binding site whereas control IgG produced only background levels. Under similar conditions, the ChIP-on-chip assay was used to assess the global and direct binding genes of $\mathrm{T}_{3} / \mathrm{TR}$. Overall, more than two thousand (2913) genes showed direct binding, 481 of which were enriched from ChIPon-chip coupled with oligonucleotide microarray of genes in hepatoma cultures treated with $\mathrm{T}_{3}$ (5246 genes) (Figure 1C). Among these, 304 up- and 176 down-regulated genes were directly bound and modulated by $\mathrm{T}_{3} / \mathrm{TR}$.
To determine the functions of the 481 identified genes, bioinformatics pathway analysis (DAVID) was performed. Upregulated genes (304) were involved in cell metabolism pathways, such as PPAR- $\alpha$ signaling, pyruvate metabolism and lysosome degradation, while downregulated genes (176) were linked to cancerassociated pathways, such as Wnt signaling, DNA replication and repair. We additionally validated direct binding and regulation by $\mathrm{T}_{3} / \mathrm{TR}$ of the two known up- and downregulated genes, PPAR- $\alpha$ [24] and $c-M Y C$ [25-27], respectively (Figure $\mathrm{S} 1$ ). Our results support the theory that $\mathrm{TR} \alpha 1$ protein binds the promoter regions of these target genes for transcriptional regulation.

\section{Genes directly bound and positively regulated by $\mathbf{T}_{3} / \mathbf{T R}$}

To validate ChIP-on-chip data, the top 50 ranking genes were selected. Overall, $92 \%$ of genes (46/50) that directly interact with TR were verified. However, among these genes, $84.78 \%(39 / 46)$ were truly regulated by $\mathrm{T}_{3} / \mathrm{TR}$. Furthermore, 28 of $33(84.85 \%)$ genes were upregulated. Symbolic genes, such as $A D O R 2 A 2, C M I P$, SELT, FURIN, TPCN1 and TP53I3 directly interacted with and were rapidly and positively regulated by $\mathrm{T}_{3} / \mathrm{TR}$ (Figure 2A, 2B). Other genes, such as GAS6, KLC2, HGS, FGFR3, PPAR- $\alpha$ and SLC16A6 bound directly and were positively regulated, but at a slower rate (Figure $2 \mathrm{C}, 2 \mathrm{D})$.

\section{Genes directly bound and negatively regulated by $T_{3} / T R$}

According to the ChIP-on-chip database, 11 of $13(84.85 \%)$ genes bound directly and were rapidly downregulated, including $S O X 9, D D A H 2, S F 3 A 2$ and $R A P 2 B$ (Figure 3A, 3B), while WHSC1, HSPA12A, $c-M Y C, I T I H 5, T A F 6 L$ and $E L F 2$ bound directly but were negatively regulated at a slower rate (Figure 3C, 3D). Taken together, the results support the high accuracy of our database and confirm the identities of specific genes directly regulated by $\mathrm{T}_{3} / \mathrm{TR}$ in hepatoma cells.

\section{$\mathrm{T}_{3} / \mathrm{TR}$ supresses cell proliferation in vitro and in vivo}

Pathway analysis suggested that $\mathrm{T}_{3} / \mathrm{TR}$ suppresses the proliferation of cancer cells. To further examine this theory, HepG2 and J7 cell lines stably expressing high levels of wild-type TR $\alpha 1$ (HepG2-TR $\alpha 1$ and J7$\mathrm{TR} \alpha 1$, respectively) were established. Notably, the proliferation ability of HepG2-TR $\alpha 1$ and J7-TR $\alpha 1$ cells was significantly suppressed upon $\mathrm{T}_{3}$ stimulation (Figure 4A, 4B left panel). Moreover, the cell cycle of HepG2-TR $\alpha 1$ and J7-TR $\alpha 1$ cells was arrested at the G1 phase following $\mathrm{T}_{3}$ treatment (Figure 4A, 4B right 
panel). To verify whether the in vitro effect of $\mathrm{T}_{3} / \mathrm{TR}$ can be replicated in vivo, nude mice were injected with $\mathrm{J} 7$ $\mathrm{TR} \alpha 1$ cells following by $\mathrm{T}_{3}$ stimulation. Higher $\mathrm{T}_{3}$ levels (hyperthyroid conditions) induced suppression of tumor weight and volume, compared to that in control mice (euthyroid conditions) (Figure 4C). Both our in vitro and in vivo findings support the potential utility of $\mathrm{T}_{3} / \mathrm{TR}$ as a target for effective suppression of cancer cell proliferation.

(A)

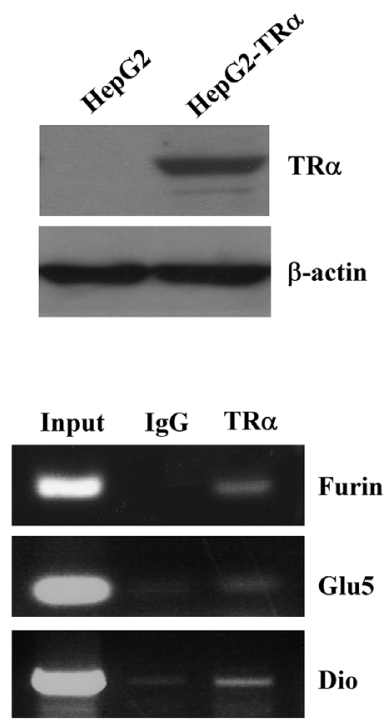

(C)

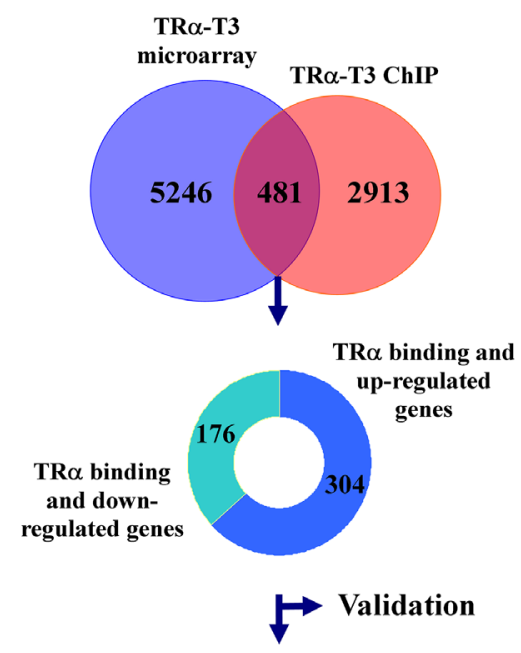

Pathway Analysis

\section{$T_{3} / T R$ suppresses cell growth via downregulation of ELF2}

ELF2 is a transcription factor that promotes cancer cell proliferation [28]. According to our database, ELF2 is directly bound and downregulated by $\mathrm{T}_{3} / \mathrm{TR}$ (Figure $5 \mathrm{~A}$ ). To determine the mechanism underlying the association of $\mathrm{T}_{3} / \mathrm{TR}$ with ELF2 function in proliferation, ELF2 was

(B)
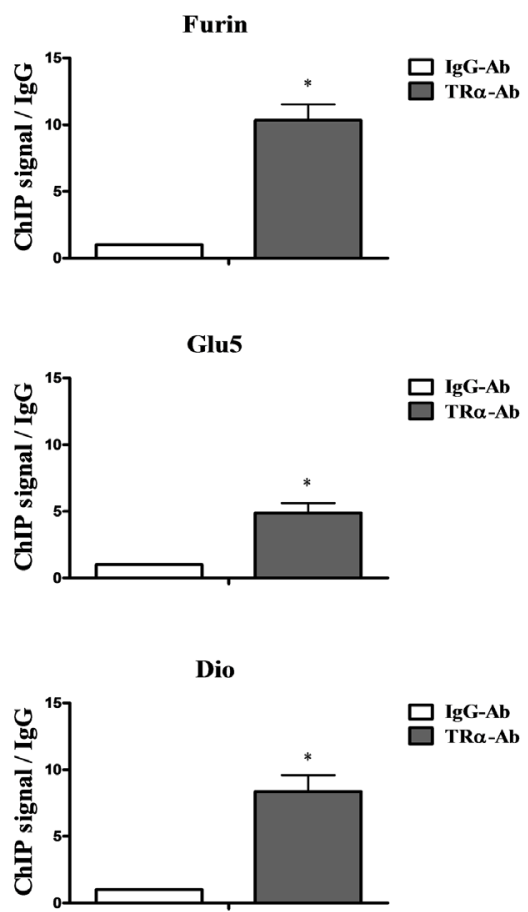

(D)

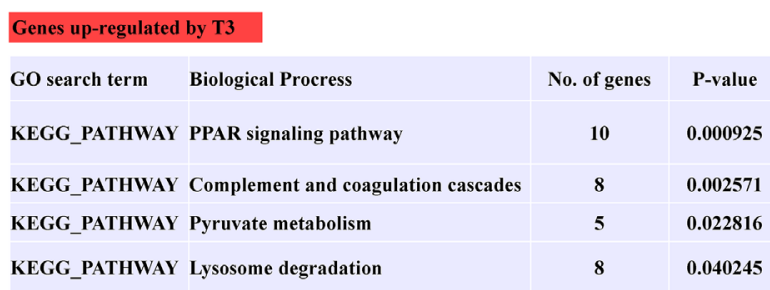

Genes down-regulated by $\mathrm{T} 3$

\begin{tabular}{|c|c|c|c|}
\hline GO search term & Biological Procress & No. of genes & P-value \\
\hline KEGG_PATHWAY & DNA replication & 4 & 0.010987 \\
\hline KEGG_PATHWAY & Wnt signaling pathway & 7 & 0.013014 \\
\hline KEGG_PATHWAY & Nucleotide excision repair & 4 & 0.018939 \\
\hline KEGG_PATHWAY & Pathways in cancer & 4 & $\mathbf{0 . 0 2 9 3 7 7}$ \\
\hline
\end{tabular}

Figure 1: Schematic diagram of ChIP-on-chip analysis. A. Western blot analysis of TR expression in extracts of TR 1 1overexpressing cell lines. The positions of $47 \mathrm{kDa}$ TR $\alpha 1$ are indicated. ChIP assay demonstrating that TR $\alpha 1$ is recruited to the TRE regions of positive control genes (FURIN, GLU5 and DIO) using RT-PCR and B. q-RT-PCR, respectively. C. Overlapping genes between ChIPon-chip and oligonucleotide microarray in $\mathrm{T}_{3}$-treated conditions. D. Functional pathways of genes directly regulated by $\mathrm{T}_{3} / \mathrm{TR}$. Differences were analyzed using one-way ANOVA, $* P<0.05$. 
overexpressed in J7 and HepG2-TR $\alpha 1$ cell lines. J7 cells overexpressing ELF2 displayed significantly increased proliferation, compared with control cells (Figure 5B), along with markedly decreased expression levels of two cell growth inhibitory genes, p21 [29, 30] and p27 [31, 32] ( $\sim 0.4$ to 0.6 and $\sim 0.3$ to 0.5 -fold, respectively) (Figure 5D). Moreover, both p21 and p27 were downregulated by $\mathrm{T}_{3} / \mathrm{TR}$ (Figure $5 \mathrm{E}$ ). Notably, the proliferative ability of HepG2-TR $\alpha 1$ control cells ( $\mathrm{T}_{3} 0 \mathrm{nM}$, pcDNA3.0) was markedly suppressed under $T_{3}$ stimulation $\left(T_{3} 10\right.$ $\mathrm{nM}$, pcDNA3.0), but restored upon ELF2 re-expression
(HepG2-TR $\alpha 1$-ELF2) (Figure 5C). The observed $\mathrm{T}_{3}$ induced inhibition of cancer cell growth and ELF2 expression supports the hypothesis that $\mathrm{T}_{3} / \mathrm{TR}$ suppresses tumor proliferation via ELF2 regulation.

\section{ELF2 depletion suppresses cell growth through p21 and p27 signaling}

To determine the consequences of ELF2 depletion, SK-HEP1 control cell lines and shLuc and ELF2 knockdown lines (shELF2\#1 and shELF2\#2) were
(A)
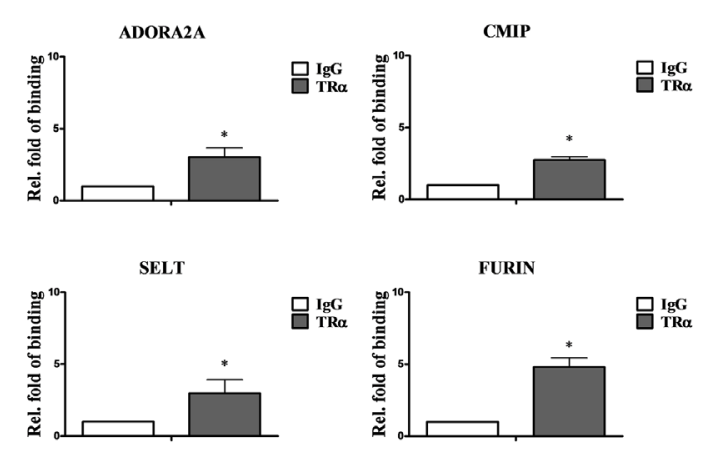

$\stackrel{\operatorname{IgG}}{\mathrm{IR} \alpha}$
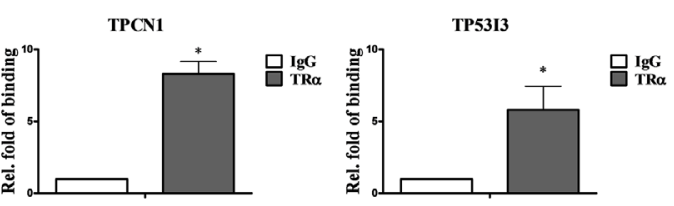

(C)
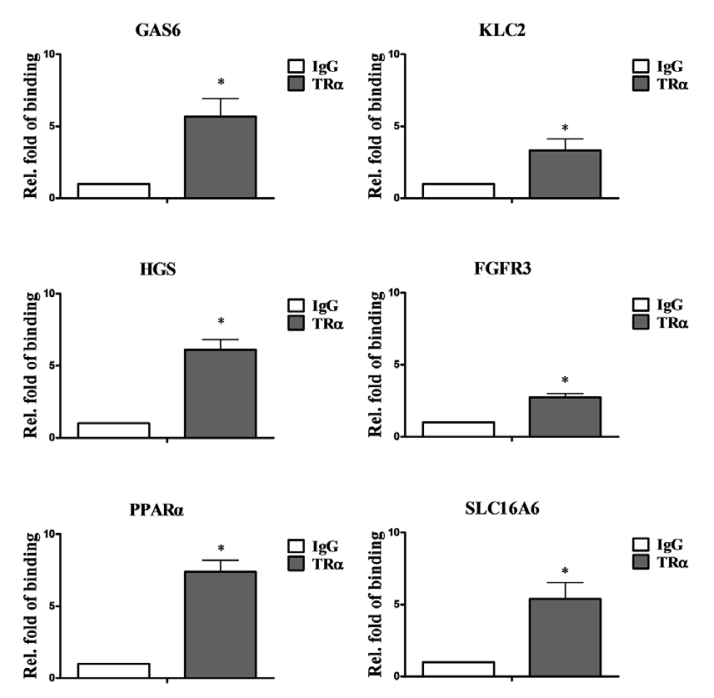
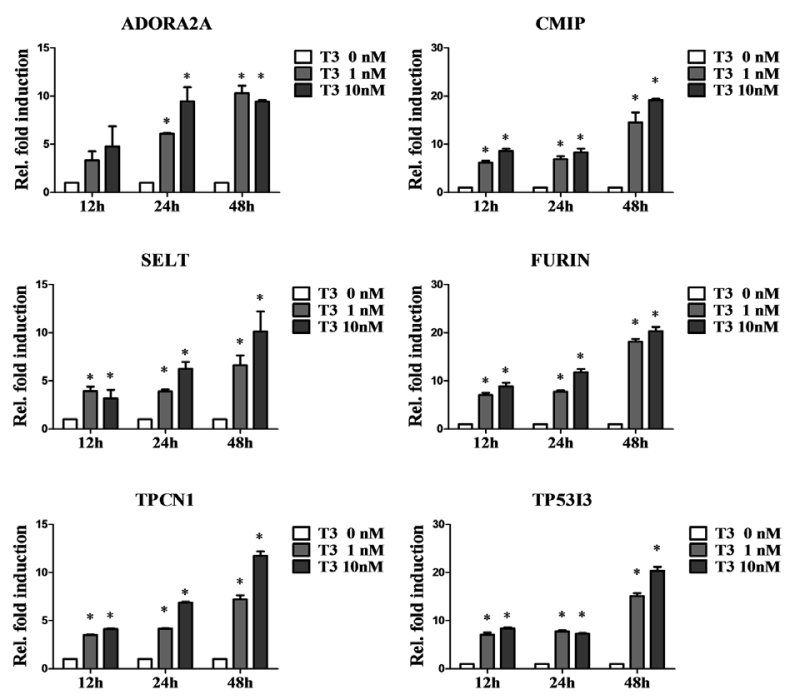

(B)

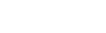

(D)
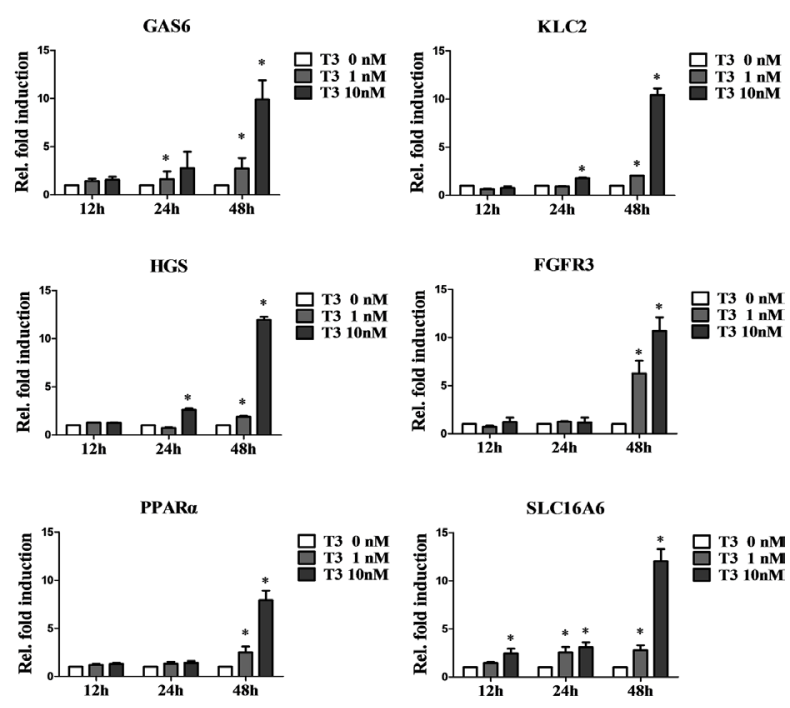

Figure 2: Genes positively regulated by $\mathbf{T}_{3} /$ TR. A. Relative binding fold, B. q-RT-PCR assessment of expression of $\mathrm{T}_{3} / \mathrm{TR}-$ upregulated genes with rapid responses $(12-48 \mathrm{~h})$ in the absence or presence of 1 or $10 \mathrm{nM} \mathrm{T}_{3}$ in HepG2-TR $\alpha 1$ cells $\mathbf{C}, \mathbf{D}$. T $/ 3$ TR-upregulated genes with delayed responses. Differences were analyzed using one-way ANOVA, ${ }^{*} P<0.05$. 
established (Figure 6A, upper panel). After depletion of ELF2, proliferation of SK-HEP1 cells was decreased, compared with control cells (Figure 6C, upper panel), confirming the ability of ELF2 to accelerate tumor cell growth. Moreover, ELF2-depleted cells were arrested at the G1 phase, consistent with the effects of $T_{3}$ (Figure $6 \mathrm{C}$, lower panel). Accordingly, we further examined whether p21 and p27 activation are implicated in ELF2depleted phenotypes. Marked upregulation of p21 and p27 was observed in ELF2-depleted cells (shELF2\#1 and shELF2\#2), compared with control cells (shLuc) (Figure 6A, 6B). Our findings suggest that stimulation

(A)
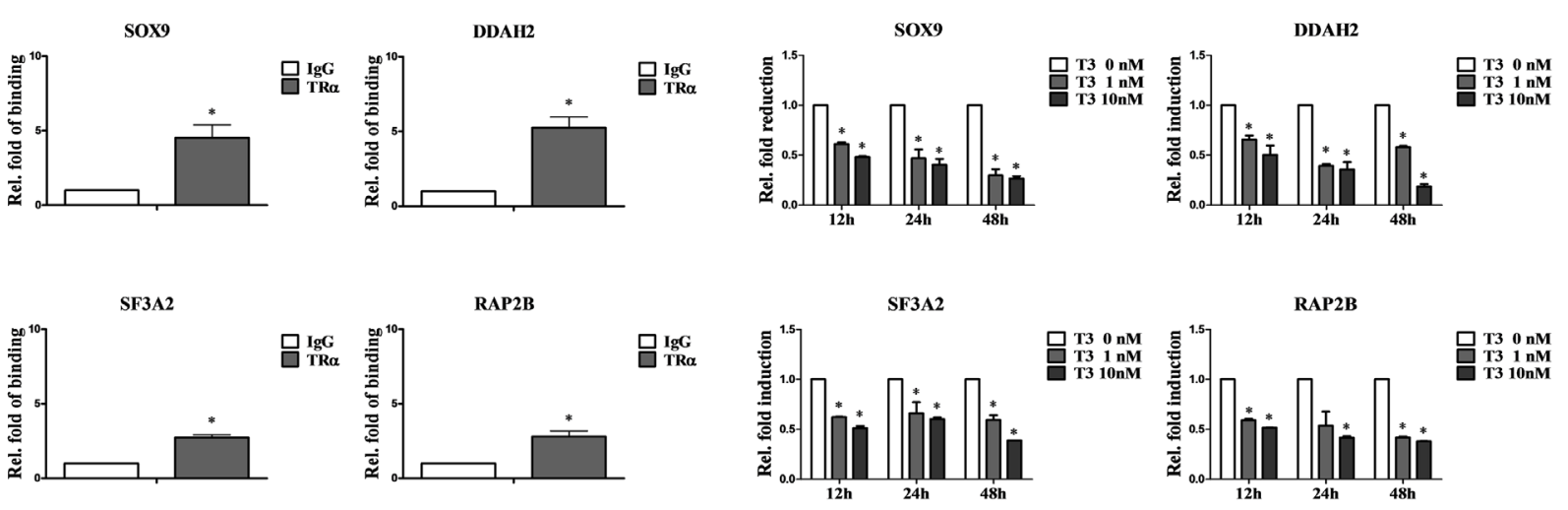

(C)
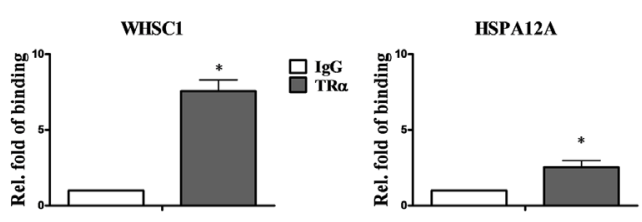

(D)
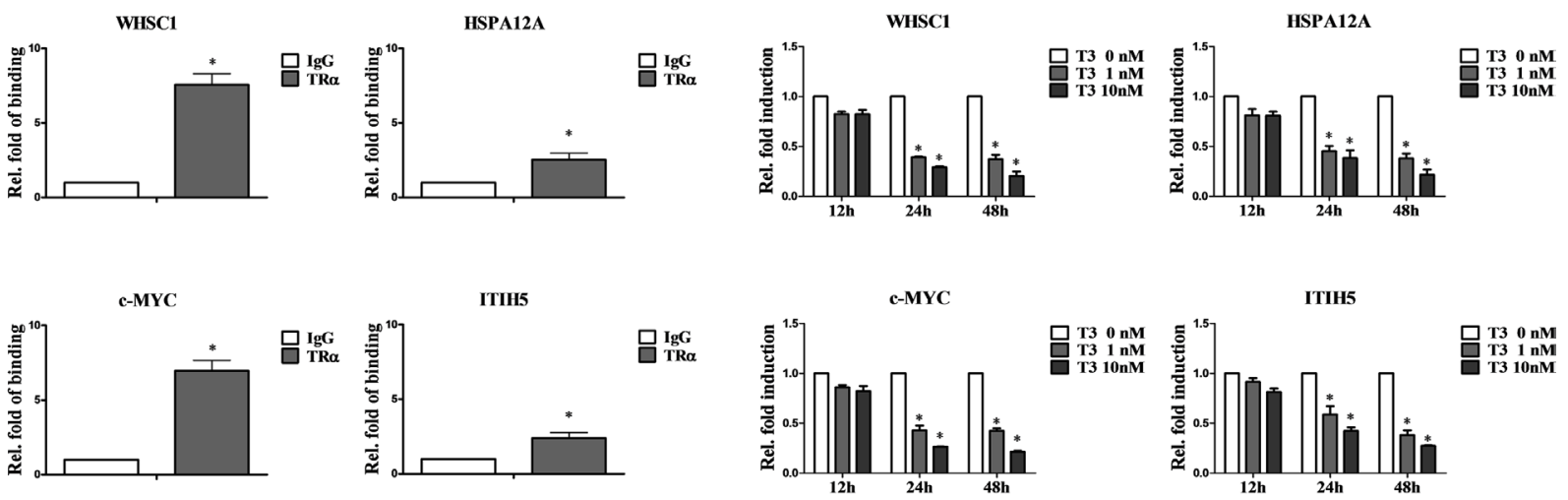

TAFGL
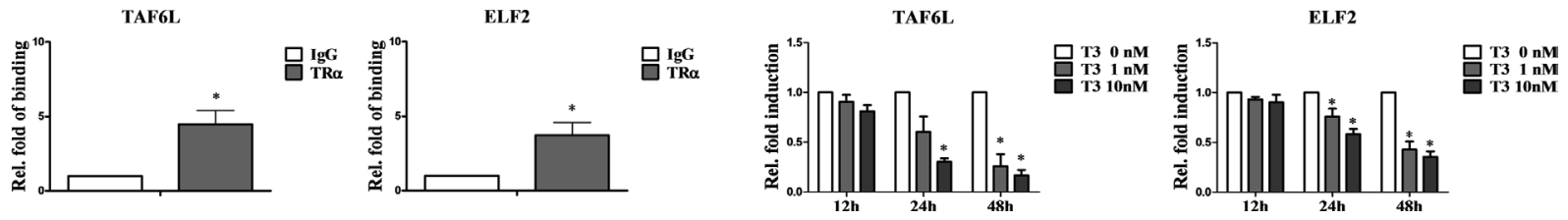

Figure 3: Genes negatively regulated by $\mathbf{T}_{3} /$ TR. A. Relative binding fold, B. q-RT-PCR assessment of expression levels of $\mathrm{T}_{3} /$ TR- downregulated genes with rapid responses (12-48 h) in the absence or presence of 1 or $10 \mathrm{nM} \mathrm{T}_{3}$ in HepG2-TR $\alpha 1$ cells $\mathbf{C}_{\text {, D. }} \mathrm{T}_{3} / \mathrm{TR}$ downregulated genes with delayed responses. Differences were analyzed using one-way ANOVA, ${ }^{*} P<0.05$. 
bound with increased affinity, depending on the presence of ligand. Importantly, integration with microarray data showed that TR $\alpha 1$ binding significantly correlated with expression patterns of target genes transcriptionally regulated by $\mathrm{T}_{3}$. In this study, we identified TR $\alpha 1$ binding sites associated with 50 genes in HepG2-TR $\alpha 1$ cells. Binding sites may be located in different genomic contexts (both upstream and downstream of the gene and within introns) and may not adhere to conventional sequence motifs (Supplementary Table). Our findings support the notion that the thyroid hormone can regulate several genes through direct binding by TR.

The Ets family of proteins consists of a number of transcription factors that share a conserved winged helixturn-helix DNA binding domain (Ets domain). Ets factors are critical mediators of a variety of cellular processes,

(A)
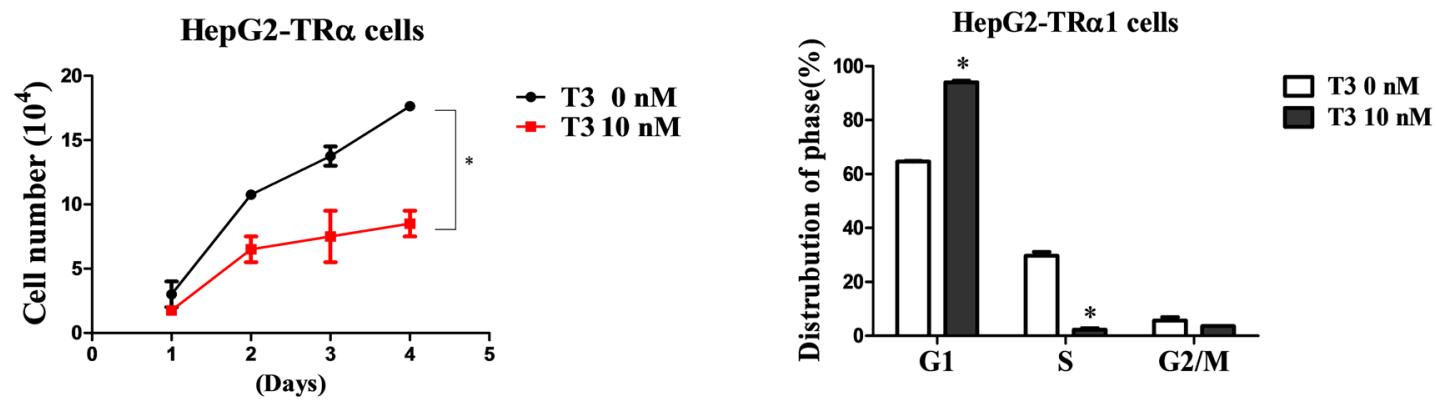

(B)
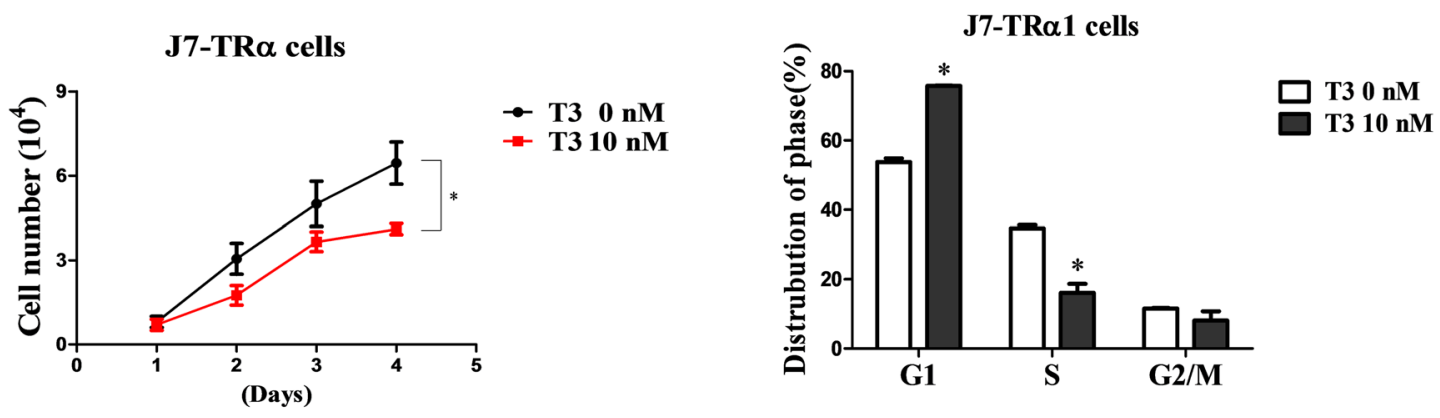

(C)
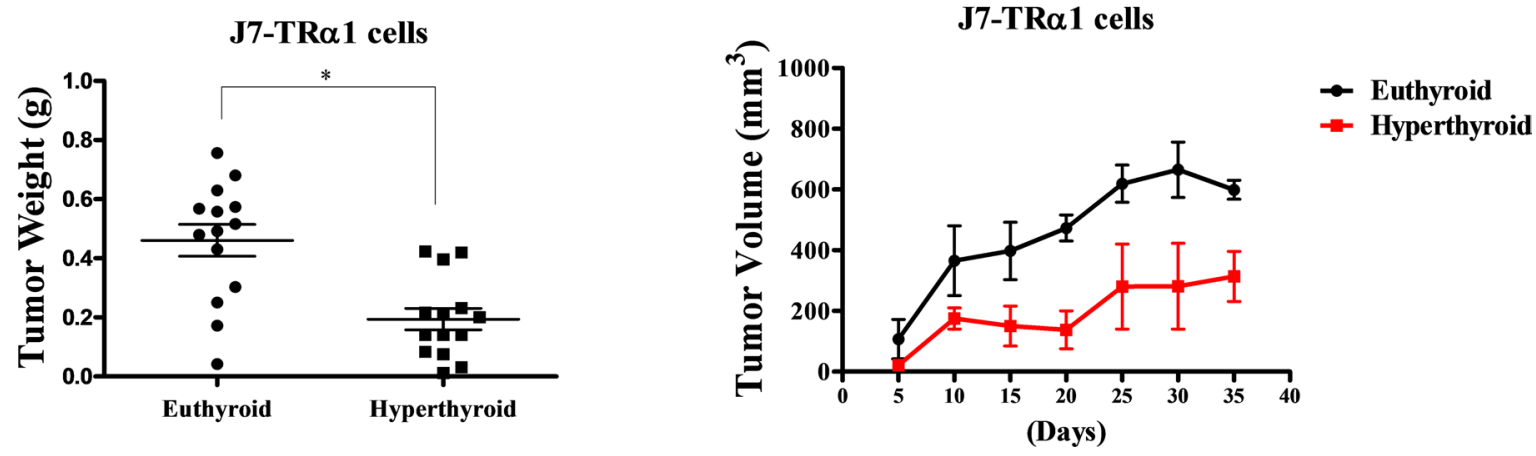

Figure 4: $\mathbf{T}_{3} / \mathrm{TR}$ suppresses cell proliferation and the cell cycle in vitro and in vivo. Cell growth ability and cell cycle were analyzed in two TR $\alpha 1$-overexpressing A. HepG2 and B. J7 cell lines in the absence or presence of $10 \mathrm{nM} \mathrm{T}$. The number of cells was counted to determine proliferation activity. The cell cycle stage was detected via flow cytometry. C. Tumor weights and volumes of nude mice injected with J7-TR $\alpha 1$ cells treated with high levels of $\mathrm{T}_{3}$ (hyperthyroid) and administered normal drinking water (euthyroid). Differences were analyzed using one-way ANOVA, $* P<0.05$. 
including development, differentiation, growth, and transformation [18]. Some Ets genes may be involved in specific chromosomal translocations in different cancer types [33], suggesting an oncogenic role. Indeed, overexpression of several Ets genes has been reported in cancers of the thyroid, pancreas, liver, colon, lung, and leukemia [34]. ELF2 belongs to the Elf subfamily of Ets transcription factors together with ELF1 and myeloid elf-1-like factor (MEF), and regulates a set of genes in B cells and myeloid cells [35]. Moreover, ELF2 physically interacts with acute myeloid leukemia 1 (AML1), a frequent target for chromosomal translocations in leukemia [36]. ELF2 expression is increased in endothelial cells in response to hypoxia and angiopoietin-1 [37]. While these findings suggest an oncogenic role of ELF2, its precise role in tumorigenesis has not been clarified as yet. In the current study, we showed that ELF2 is modulated by $\mathrm{T}_{3}$ at both mRNA and protein levels. Our experiments confirmed that $\mathrm{T}_{3}$ regulates $E L F 2$ at the transcriptional level and TR proteins directly bind TRE of the ELF2

(A)
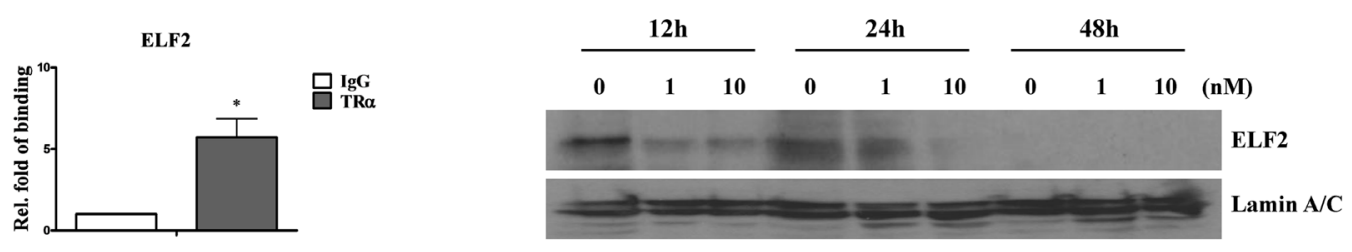

(B)

(C)
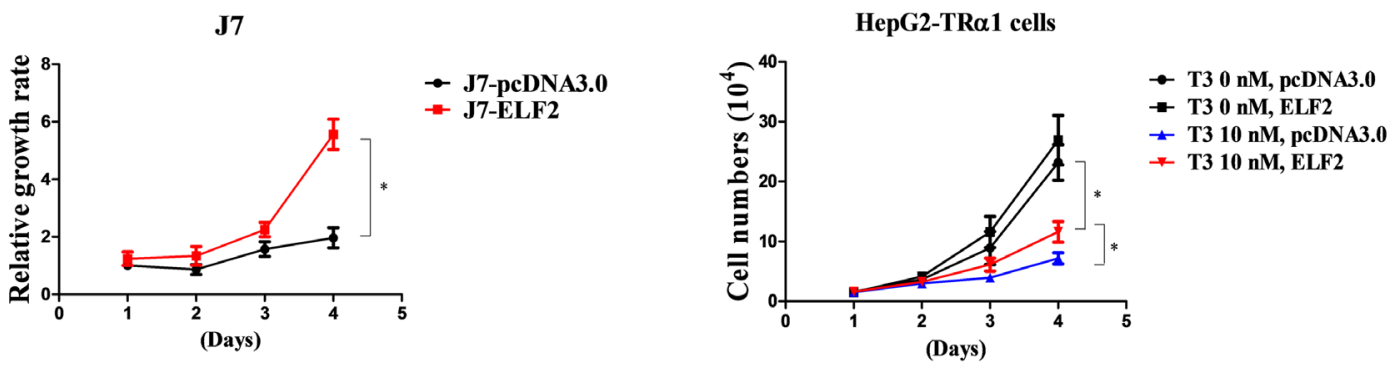

(D)
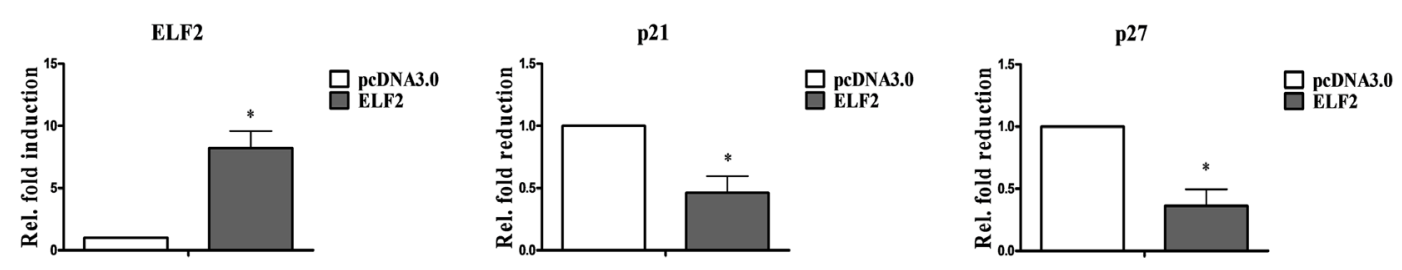

(E)
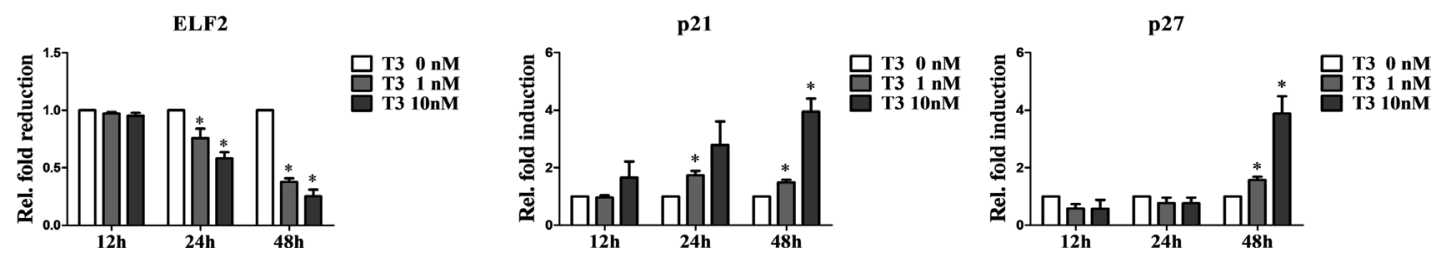

Figure 5: ELF2 is negatively regulated by $\mathbf{T}_{3} /$ TR to suppress cell proliferation. A. ChIP assay demonstrating that TR $\alpha 1$ is recruited to the ELF2 TRE (left panel). Western blot analysis of ELF2 protein expression in stable HepG2-TR 1 cell lines at $12-48 \mathrm{~h}$ in the absence or presence of 1 and $10 \mathrm{nM} \mathrm{T}_{3}$ (right panel). B. Cell proliferation analysis via cell counting in ELF2-overexpressing and control J7 cell lines. C. ELF2 overexpression rescues the proliferation activity of HepG2-TR $\alpha 1$ cells at $48 \mathrm{~h}$ in the absence or presence of $10 \mathrm{nM} \mathrm{T}_{3}$. q-RT-PCR detection of p21 and p27 in ELF2-overexpressing, compared to vector control-expressing D. J7 cells or E. HepG2-TR $\alpha 1$ cells in similar $\mathrm{T}_{3}$ conditions. Differences were analyzed using one-way ANOVA, ${ }^{*} P<0.05$. 
promoter region. Notably, cell lines overexpressing ELF2 displayed higher proliferation. Moreover, $\mathrm{T}_{3}$-mediated suppression of ELF2 occurred via p21 and p27 activation, leading to inhibition of cancer cell progression.

(A)

ELF2

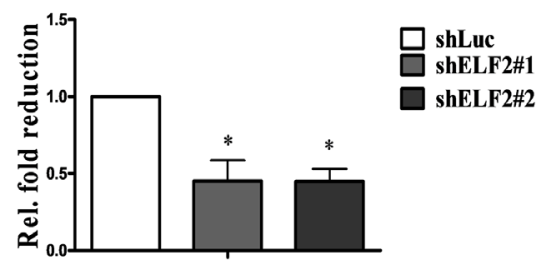

p21
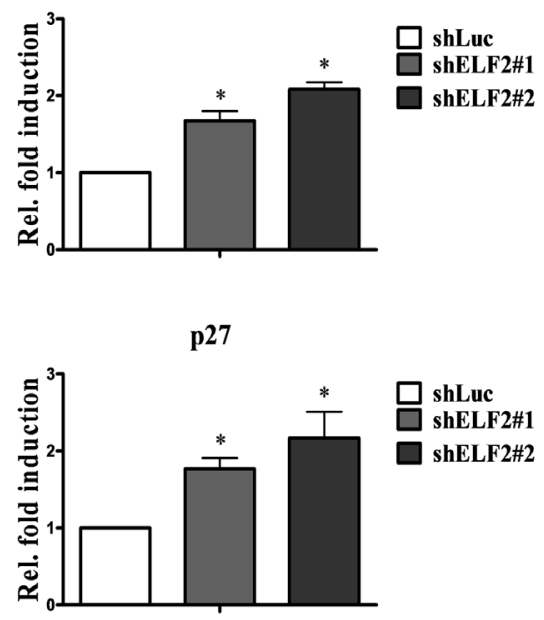

(B)

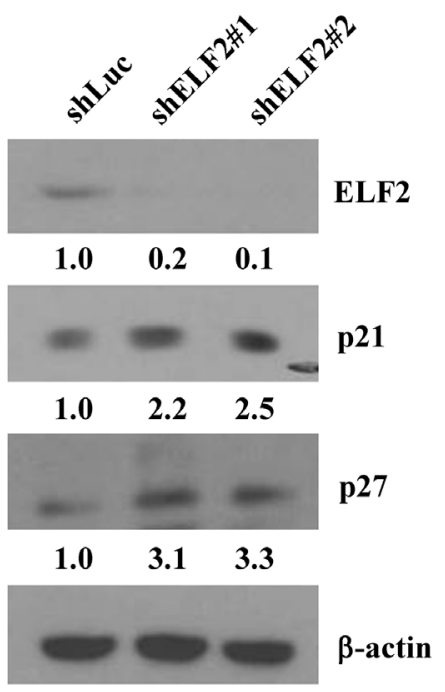

The liver is a typical target organ of thyroid hormones (THs). Equal amounts of TR $\alpha 1$ and TR $\beta 1$ proteins are expressed in human hepatocytes. Recent studies have suggested that long-term hypothyroidism

(C)

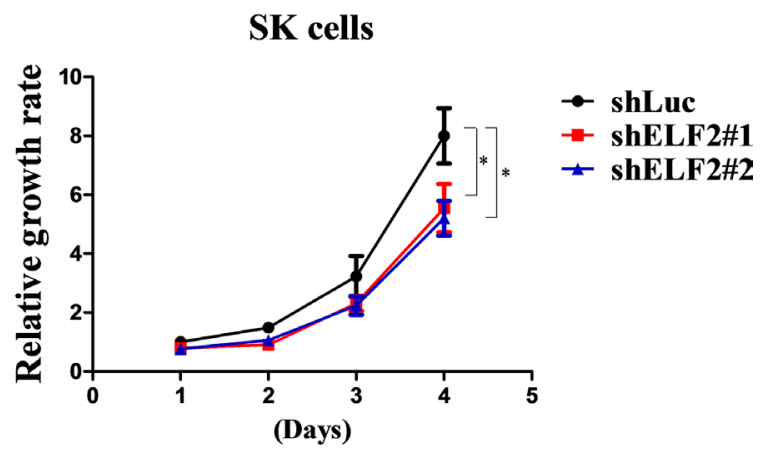

SK cells

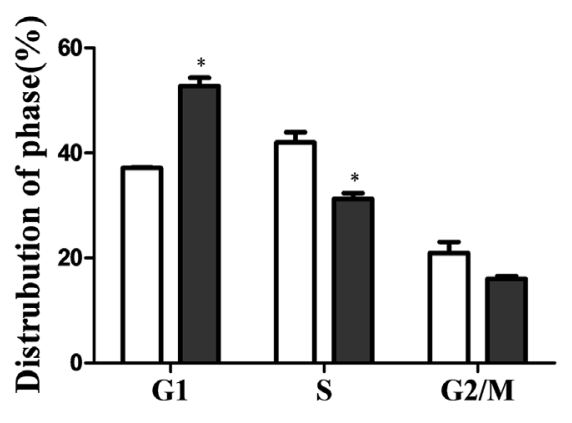

(D)

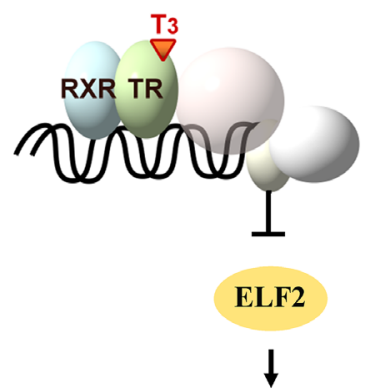

p21/p27 activation

$\downarrow$

Cell growth inhibition

Figure 6: ELF2 depletion suppresses cell proliferation via p21 and p27 activation. Detection of ELF2, p21 and p27 expression in ELF2-depleted (shELF2\#1, shELF2\#2) and control (shLuc) SK-Hep1 cells using A. q-RT-PCR and B. western blot, respectively. C. Cell proliferation analysis in ELF2-depleted (shELF2\#1, shELF2\#2) and control (shLuc) SK-Hep1 cells (upper panel). Cell cycle stages of ELF2depleted (shELF) and control (shLuc) SK-Hep1 cells detected via flow cytometry (lower panel). D. Schematic diagram showing that $\mathrm{T}_{3} / \mathrm{TR}$ negatively regulates ELF2 to suppress cell proliferation via p21/p27 activation. Differences were analyzed using one-way ANOVA, $* P<0.05$. 
is associated with $\mathrm{HCC}$, independent of other major HCC risk factors [38]. Hypothyroidism is characterized by insufficient production of THs and inappropriate TR action and is a possible risk factor in human cancers. However, no results directly showing that thyroid status is associated with tumor progression have been reported as yet. Earlier studies demonstrated that liver function abnormalities return to normal once primary thyroid pathology is recognized and treated [39]. Subsequently, $\mathrm{T}_{3}$ was shown to mediate apoptosis and accelerate necrosis in liver cells [40]. These results suggest that hypothyroidism increases the risk of liver cancer through decreased apoptosis in the liver lesion process. Another group showed that hypothyroidism is associated with high risk of HCC in women [38]. However, the mechanisms linking hypothyroidism with $\mathrm{HCC}$ need to be clarified with further studies on different population groups.

In conclusion, $\mathrm{T}_{3}$ induces an increase in $\mathrm{TR} \alpha 1$ binding, leading to either positive or negative regulation of target genes. The results of this study provide new insights into the mechanisms of transcriptional regulation by $\mathrm{TR} \alpha 1: \mathrm{T}_{3}$-mediated negative regulation of ELF2 may contribute to reduction of hepatoma cell growth through subsequent activation of the cell cycle checkpoint.

\section{MATERIALS AND METHODS}

\section{Cell culture}

Human hepatoma cells, HepG2, SK-Hep1 and $\mathrm{J} 7$, were routinely cultured at $37^{\circ} \mathrm{C}$ in a humidified atmosphere of $95 \%$ air and $5 \% \mathrm{CO}_{2}$ in Dulbecco's modified Eagle's medium (DMEM) supplemented with $10 \%$ fetal bovine serum (FBS). HepG2 and $\mathrm{J} 7$ cell lines were stably transfected with TR $\alpha 1$ (HepG2-TR $\alpha 1$ and J7TR $\alpha 1)$.

\section{Chromatin immunoprecipitation (ChIP) assay}

HepG2-TR $\alpha 1$ cells treated with $10 \mathrm{nM} \mathrm{T}_{3}$ for 24 $\mathrm{h}$ or left untreated were harvested and cross-linked with $1 \%$ formaldehyde for $10 \mathrm{~min}$ at room temperature in DMEM. Reactions were terminated with the addition of $0.125 \mathrm{M}$ glycine. Subsequently, cell lysates were washed three times with PBS and resuspended in lysis buffer

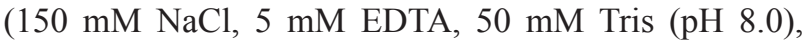
$0.1 \%$ SDS and $0.1 \%$ sodium deoxycholate) containing three protease inhibitors (1 $\mathrm{mM}$ PMSF, aprotinin, and leupeptin). Cell lysates were sonicated with a Misonix Sonicator 3000 Homogenizer (Mandel Scientific Company Inc., Guelph, ON, Canada) to disrupt chromatin. Sonicated DNA was between 200 and 1000 bp in length. Products were precleared with $60 \mu \mathrm{l}$ protein $\mathrm{A} / \mathrm{G}$ agarose (Sigma Chemicals, St. Louis, MO) for $2 \mathrm{~h}$ at $4^{\circ} \mathrm{C}$. Complexes were immunoprecipitated with anti-TR (kindly provided by the laboratory of Dr. S-Y Cheng at the National Cancer
Institute) and anti-IgG antibodies (R\&D Systems, Inc., Minneapolis, MN). Enriched targets were hybridized to promoter microarrays (Welgene Biotech, ChIP-on-chip microarray) spanning $-8 \mathrm{~kb}$ to $+2 \mathrm{~kb}$ of the transcription start site (TSS) of 35000 genes. The promoter fragments of target gene containing the TRE region were detected via q-RT-PCR. All of primers were listed at Supplementary Table.

\section{Cloning of ELF2}

cDNA was synthesized from total RNA ( $1 \mu \mathrm{g})$ using Superscript II reverse transcriptase (Invitrogen, Carlsbad, CA) and oligo (dT) primers. ELF2 was amplified from cDNA by polymerase chain reaction (PCR) using the primer pair 5'-ATG GCG ACG TCT CTG CAT GAG GGA C-3' (forward) and 5'-TTA TTT CTC ACA TGT CAC TAG TCC T-3' (reverse), and the following thermocycling conditions: 30 cycles at $95^{\circ} \mathrm{C}$ for $1 \mathrm{~min}, 58^{\circ} \mathrm{C}$ for $1 \mathrm{~min}$, and $72^{\circ} \mathrm{C}$ for $2 \mathrm{~min}$. The $E L F 2$ open reading frame was ligated into the pcDNA 3.0 expression vector, and the resulting construct was sequenced to confirm the presence of the gene.

\section{Establishing $\mathbf{J} 7$ cell lines stably overexpressing ELF2}

The $\mathrm{J} 7$ cell line, grown in $10-\mathrm{cm}$ cell culture dishes, was transfected with the ELF2 expression plasmid using the Lipofectamine reagent (Invitrogen). After $24 \mathrm{~h}$, transformants were selected from transfected cells by growing in medium containing the antibiotic G418 (400 $\mu \mathrm{g} / \mathrm{ml})$. Expression of ELF2 protein in the selected clones was detected using Western blot analysis.

\section{shRNA-mediated ELF2 knockdown}

Short hairpin RNA (shRNA) sequences targeting ELF2 were purchased from the National RNAi Core Facility (Institute of Molecular Biology, Academia Sinica, Taiwan). The SK-HEP1 line was transiently transfected with shRNA targeting the endogenous ELF2 gene using the Turbofect reagent (Invitrogen). ELF2 repression was confirmed by Western blot analysis.

\section{Immunoblot analysis}

Total cell lysates were prepared, and protein concentrations determined with the Bradford assay kit (Pierce Biotechnology, Rockford, IL). Equivalent amounts of proteins were fractionated on a $10 \%$ sodium dodecyl sulfate (SDS)-polyacrylamide gel. Separated proteins were transferred to nitrocellulose membrane $(\mathrm{pH} 7.9$, Amersham Biosciences Inc., Piscataway, NJ), blocked with $5 \%$ non-fat powdered milk, and incubated with specific anti-ELF2 (GeneTex; GTX104851), anti-p21 (abcam; ab109520), anti-p27 (abcam; ab32034), anti- 
c-MYC (GeneTex; GTX103436) and anti-PPAR $\alpha$ (GeneTex; GTX101098) primary antibodies at $-20{ }^{\circ} \mathrm{C}$ overnight. After washing, membranes were incubated with HRP-conjugated anti-mouse, anti-rabbit or anti-goat IgG secondary antibody, as appropriate, for $1 \mathrm{~h}$ at room temperature. Immune complexes were visualized using an enhanced chemiluminescence (ECL) detection kit (Amersham) and Fuji X-ray film.

\section{In vitro proliferation assays}

The influence of ELF2 on the cell proliferation abilities of J7-ELF2 and SK-HEP1-ELF2-depleted cells were determined. The proliferation abilities under $\mathrm{T}_{3}$ $(10 \mathrm{nM})$ condition in HepG2-TR $\alpha 1$ cells and restored by ELF2 expression were identified in vitro as described previously [20]. Briefly, cell density was adjusted to $10^{6}$ cells $/ \mathrm{ml}$, and $100 \mu \mathrm{l}$ of the suspension seeded on 24 well plate. The medium was DMEM with $10 \%$ fetal bovine serum (FBS). After incubation for $1-4$ days at $37^{\circ} \mathrm{C}$, cells harvested were examined via MTT assay or cell counting. Experiments were performed at least three times.

\section{In vivo proliferation assays}

Similar conditions were employed with nude mice containing various $\mathrm{T}_{3}$ levels induced via injection of J7-TR $\alpha 1$ cells [7]. Mice were divided into two groups, specifically, Group A (euthyroid) comprising control mice given normal drinking water and Group B (hyperthyroid) administered drinking water augmented with $\mathrm{T}_{3}(2 \mathrm{mg} / \mathrm{L})$ (Sigma Chem. Co., St. Louis, MO) after inoculation of tumor cells. Mice were sacrificed about 1 month after injection, their livers and lungs removed for tumor biopsy, and the $\mathrm{T}_{3}$ and TSH levels determined. The $\mathrm{T}_{3}$ and TSH levels in sera of euthyroid mice (Group A) were $45.5 \mathrm{ng} / \mathrm{dl}$ and $0.246 \mathrm{mIU} / \mathrm{ml}$, while those in sera of hyperthyroid mice (Group B) were $619 \mathrm{ng} / \mathrm{dl}$ and 0.008 $\mathrm{mIU} / \mathrm{ml}$, respectively. Tumor volume was calculated using the following equation: length $\times$ height $\times$ width. All procedures were performed under sterile conditions in a laminar flow hood. Animal experiments were performed in accordance with the United States National Institutes of Health guidelines and Chang-Gung Institutional Animal Care and Use Committee Guide for the Care and Use of Laboratory Animals.

\section{Cell cycle assay}

For detection of cell cycle phases, HepG2TR $\alpha 1$ cells were starved in serum-free medium for 24 $\mathrm{h}$, followed by incubation in medium with or without $\mathrm{T}_{3}$. After $24 \mathrm{~h}$, cells were harvested with trypsin and washed twice with cold phosphate-buffered saline. SKHEP1 control and SK-HEP1-ELF2-depleted cells were harvested without $\mathrm{T}_{3}$ condition. Subsequently, cells were fixed with $70 \%$ ethanol for $1 \mathrm{~h}$ at $-20^{\circ} \mathrm{C}$ and incubated in
$0.5 \%$ Triton $\mathrm{X}-100 /$ phosphate-buffered saline containing $0.05 \%$ DNase-free RNase for $1 \mathrm{~h}$ at $37^{\circ} \mathrm{C}$. Nuclei were stained with propidium iodide $(50 \mu \mathrm{g} / \mathrm{ml})$ after treatment with $0.5 \%$ Triton X-100/PBS containing 0.05\% DNasefree RNase, and the DNA content was analyzed by flow cytometry using the fluorescence-activated cell sorting Aria cell sorting system (Becton Dickinson). The percentage of cells in each phase of the cell cycle was determined using the Modfit LT program (Verity Software House).

\section{Statistical analysis}

Data are expressed as mean values \pm SEM of at least three experiments. Statistical analysis was performed using Student's $t$ test and one-way ANOVA. $P$ values $<$ 0.05 were considered statistically significant.

\section{ACKNOWLEDGMENTS}

This work is supported by grants from the Ministry of Science and Technology (MOST104-2320-B-182-029-MY3 to B.C.T., MOST103-2320-B182-018-MY3, MOST1022321-B182-003, MOST101-2321-B182-003, MOST1002321-B182-005 and MOST100-2320-B-182-029-MY3 to K.H.L.), National Health Research Institute (NHRIEX105-10321SI to B.C.T.), and Chang Gung Memorial Hospital (CMRPG3D1512 to H.L., CMRPD3E0152, CMRPD1C0843 to B.C.T., CMRPD1C0271, CMRPD $1 \mathrm{C} 0272$ and CMRPD $1 \mathrm{C} 0273$ to K.H.L.).

\section{CONFLICTS OF INTEREST}

The authors declare no conflicts of interest.

\section{REFERENCES}

1. Munoz A, Bernal J. Biological activities of thyroid hormone receptors. Eur J Endocrinol. 1997; 137:433-445.

2. Cohen K, Flint N, Shalev S, Erez D, Baharal T, Davis PJ, Hercbergs A, Ellis M, Ashur-Fabian O. Thyroid hormone regulates adhesion, migration and matrix metalloproteinase 9 activity via alphavbeta3 integrin in myeloma cells. Oncotarget. 2014; 5:6312-6322. doi: 10.18632/oncotarget.2205

3. Fabian ID, Rosner M, Fabian I, Vishnevskia-Dai V, Zloto O, Shinderman Maman E, Cohen K, Ellis M, Lin HY, Hercbergs A, Davis PJ, Ashur-Fabian O. Low thyroid hormone levels improve survival in murine model for ocular melanoma. Oncotarget. 2015; 6:11038-11046. doi: 10.18632/ oncotarget.3566

4. Lin HY, Glinsky GV, Mousa SA, Davis PJ. Thyroid hormone and anti-apoptosis in tumor cells. Oncotarget. 2015; 6:14735-14743. doi: 10.18632/oncotarget.4023

5. Cheng SY. Multiple mechanisms for regulation of the transcriptional activity of thyroid hormone receptors. Rev Endocr Metab Disord. 2000; 1:9-18. 
6. Chen CY, Chung IH, Tsai MM, Tseng YH, Chi HC, Tsai CY, Lin YH, Wang YC, Chen CP, Wu TI, Yeh CT, Tai DI, Lin KH. Thyroid hormone enhanced human hepatoma cell motility involves brain-specific serine protease 4 activation via ERK signaling. Mol Cancer. 2014; 13:162.

7. Chung IH, Chen CY, Lin YH, Chi HC, Huang YH, Tai PJ, Liao CJ, Tsai CY, Lin SL, Wu MH, Lin KH. Thyroid hormone-mediated regulation of lipocalin 2 through the Met/FAK pathway in liver cancer. Oncotarget. 2015; 6:15050-15064. doi: 10.18632/oncotarget.3670

8. Davis FB, Tang HY, Shih A, Keating T, Lansing L, Hercbergs A, Fenstermaker RA, Mousa A, Mousa SA, Davis PJ, Lin HY. Acting via a cell surface receptor, thyroid hormone is a growth factor for glioma cells. Cancer Res. 2006; 66:7270-7275.

9. Dayan CM, Panicker V. Novel insights into thyroid hormones from the study of common genetic variation. Nat Rev Endocrinol. 2009; 5:211-218.

10. Ruiz-Llorente L, Ardila-Gonzalez S, Fanjul LF, MartinezIglesias O, Aranda A. microRNAs 424 and 503 are mediators of the anti-proliferative and anti-invasive action of the thyroid hormone receptor beta. Oncotarget. 2014; 5:2918-2933. doi: 10.18632/oncotarget. 1577

11. Park JW, Zhao L, Webb P, Cheng SY. Src-dependent phosphorylation at Y406 on the thyroid hormone receptor beta confers the tumor suppressor activity. Oncotarget. 2014; 5:10002-10016. doi: 10.18632/oncotarget.2487

12. Park JW, Zhao L, Willingham M, Cheng SY. Oncogenic mutations of thyroid hormone receptor beta. Oncotarget. 2015; 6:8115-8131. doi: 10.18632/oncotarget.3466

13. Ramadoss P, Abraham BJ, Tsai L, Zhou Y, Costa-e-Sousa RH, Ye F, Bilban M, Zhao K, Hollenberg AN. Novel mechanism of positive versus negative regulation by thyroid hormone receptor betal (TRbeta1) identified by genomewide profiling of binding sites in mouse liver. J Biol Chem. 2014; 289:1313-1328.

14. Moran C, Chatterjee K. Resistance to thyroid hormone due to defective thyroid receptor alpha. Best Pract Res Clin Endocrinol Metab. 2015; 29:647-657.

15. Chatonnet F, Guyot R, Benoit G, Flamant F. Genome-wide analysis of thyroid hormone receptors shared and specific functions in neural cells. Proc Natl Acad Sci U S A. 2013; 110:E766-775.

16. Kawagoe H, Potter M, Ellis J, Grosveld GC. TEL2, an ETS factor expressed in human leukemia, regulates monocytic differentiation of U937 Cells and blocks the inhibitory effect of TEL1 on ras-induced cellular transformation. Cancer Res. 2004; 64:6091-6100.

17. Li D, Bi FF, Cao JM, Cao C, Li CY, Liu B, Yang Q. Poly (ADP-ribose) polymerase 1 transcriptional regulation: a novel crosstalk between histone modification H3K9ac and ETS1 motif hypomethylation in BRCA1-mutated ovarian cancer. Oncotarget. 2014; 5:291-297. doi: 10.18632/oncotarget.1549
18. Hsu T, Trojanowska M, Watson DK. Ets proteins in biological control and cancer. J Cell Biochem. 2004; 91:896-903.

19. Qiu Y, Morii E, Zhang B, Tomita Y, Aozasa K. E74-like factor 2 transactivates valosin-containing protein gene, a gene involved in cancer growth. Exp Mol Pathol. 2008; 84:226-229.

20. Lin YH, Huang YH, Wu MH, Wu SM, Chi HC, Liao CJ, Chen CY, Tseng YH, Tsai CY, Tsai MM, Lin KH. Thyroid hormone suppresses cell proliferation through endoglinmediated promotion of p21 stability. Oncogene. 2013; 32:3904-3914.

21. Chen RN, Huang YH, Lin YC, Yeh CT, Liang Y, Chen SL, Lin KH. Thyroid hormone promotes cell invasion through activation of furin expression in human hepatoma cell lines. Endocrinology. 2008; 149:3817-3831.

22. Matosin-Matekalo M, Mesonero JE, Laroche TJ, Lacasa M, Brot-Laroche E. Glucose and thyroid hormone co-regulate the expression of the intestinal fructose transporter GLUT5. Biochem J. 1999; 339:233-239.

23. Johnson KM, Lema SC. Tissue-specific thyroid hormone regulation of gene transcripts encoding iodothyronine deiodinases and thyroid hormone receptors in striped parrotfish (Scarus iseri). Gen Comp Endocrinol. 2011; 172:505-517.

24. Zhang N, Chu ES, Zhang J, Li X, Liang Q, Chen J, Chen M, Teoh N, Farrell G, Sung JJ, Yu J. Peroxisome proliferator activated receptor alpha inhibits hepatocarcinogenesis through mediating NF-kappaB signaling pathway. Oncotarget. 2014; 5:8330-8340. doi: 10.18632/oncotarget. 2212

25. Jackstadt R, Hermeking H. AP4 is required for mitogenand c-MYC-induced cell cycle progression. Oncotarget. 2014; 5:7316-7327. doi: 10.18632/oncotarget.2348

26. Raffeiner P, Rock R, Schraffl A, Hartl M, Hart JR, Janda KD, Vogt PK, Stefan E, Bister K. In vivo quantification and perturbation of Myc-Max interactions and the impact on oncogenic potential. Oncotarget. 2014; 5:8869-8878. doi: 10.18632/oncotarget.2588

27. Yao Y, Li C, Zhou X, Zhang Y, Lu Y, Chen J, Zheng X, Tao D, Liu Y, Ma Y. PIWIL2 induces c-Myc expression by interacting with NME2 and regulates c-Myc-mediated tumor cell proliferation. Oncotarget. 2014; 5:8466-8477. doi: 10.18632/oncotarget.2327

28. Zhang B, Tomita Y, Qiu Y, He J, Morii E, Noguchi S, Aozasa K. E74-like factor 2 regulates valosin-containing protein expression. Biochem Biophys Res Commun. 2007; 356:536-541.

29. Liu X, Yang WT, Zheng PS. Msi1 promotes tumor growth and cell proliferation by targeting cell cycle checkpoint proteins p21, p27 and p53 in cervical carcinomas. Oncotarget. 2014; 5:10870-10885. doi: 10.18632/oncotarget.2539

30. Popovics P, Schally AV, Szalontay L, Block NL, Rick FG. Targeted cytotoxic analog of luteinizing hormone-releasing hormone (LHRH), AEZS-108 (AN-152), inhibits the growth of DU-145 human castration-resistant prostate cancer in vivo 
and in vitro through elevating p21 and ROS levels. Oncotarget. 2014; 5:4567-4578. doi: 10.18632/oncotarget.2146

31. Jezkova J, Williams JS, Jones-Hutchins F, Sammut SJ, Gollins S, Cree I, Coupland S, McFarlane RJ, Wakeman JA. Brachyury regulates proliferation of cancer cells via a p27Kip1-dependent pathway. Oncotarget. 2014; 5:38133822. doi: 10.18632/oncotarget.1999

32. Zhao H, Faltermeier CM, Mendelsohn L, Porter PL, Clurman BE, Roberts JM. Mislocalization of p27 to the cytoplasm of breast cancer cells confers resistance to antiHER2 targeted therapy. Oncotarget. 2014; 5:12704-12714. doi: 10.18632/oncotarget.2871

33. Annala M, Kivinummi K, Tuominen J, Karakurt S, Granberg K, Latonen L, Ylipaa A, Sjoblom L, Ruusuvuori P, Saramaki O, Kaukoniemi KM, Yli-Harja O, Vessella RL, et al. Recurrent SKIL-activating rearrangements in ETSnegative prostate cancer. Oncotarget. 2015; 6:6235-6250. doi: 10.18632/oncotarget.3359

34. Seth A, Watson DK. ETS transcription factors and their emerging roles in human cancer. Eur J Cancer. 2005; 41:2462-2478.

35. Oettgen P, Akbarali Y, Boltax J, Best J, Kunsch C, Libermann TA. Characterization of NERF, a novel transcription factor related to the Ets factor ELF-1. Mol Cell Biol. 1996; 16:5091-5106.
36. Cho JY, Akbarali Y, Zerbini LF, Gu X, Boltax J, Wang Y, Oettgen P, Zhang DE, Libermann TA. Isoforms of the Ets transcription factor NERF/ELF-2 physically interact with AML1 and mediate opposing effects on AML1-mediated transcription of the B cell-specific blk gene. J Biol Chem. 2004; 279:19512-19522.

37. Christensen RA, Fujikawa K, Madore R, Oettgen P, Varticovski L. NERF2, a member of the Ets family of transcription factors, is increased in response to hypoxia and angiopoietin-1: a potential mechanism for Tie2 regulation during hypoxia. J Cell Biochem. 2002; 85:505-515.

38. Hassan MM, Kaseb A, Li D, Patt YZ, Vauthey JN, Thomas MB, Curley SA, Spitz MR, Sherman SI, Abdalla EK, Davila M, Lozano RD, Hassan DM, Chan W, Brown TD, Abbruzzese JL. Association between hypothyroidism and hepatocellular carcinoma: a case-control study in the United States. Hepatology. 2009; 49:1563-1570.

39. Bayraktar M, Van Thiel DH. Abnormalities in measures of liver function and injury in thyroid disorders. Hepatogastroenterology. 1997; 44:1614-1618.

40. Upadhyay G, Singh R, Kumar A, Kumar S, Kapoor A, Godbole MM. Severe hyperthyroidism induces mitochondria-mediated apoptosis in rat liver. Hepatology. 2004; 39:1120-1130. 